Mallett O \& Wapshott R (2015) Contesting the history and politics of enterprise and entrepreneurship, Work, Employment and Society, 29 (1), pp. 177-182. Copyright @ Authors 2014 (Copyright Holder). Reprinted by permission of SAGE Publications.

\title{
Contesting the history and politics of enterprise and entrepreneurship
}

Oliver Mallett, Durham University Business School

Robert Wapshott, Sheffield University Management School

Mark Casson and Catherine Casson

The Entrepreneur in History: From Medieval Merchant to Modern Business Leader Basingstoke: Palgrave Macmillan, 2013, £45 hbk, (9781137305817), 148pp.

David Landes, Joel Mokyr \& William Baumol (Eds.)

The Invention of Enterprise: Entrepreneurship from Ancient Mesopotamia to Modern Times

Princeton, NJ: Princeton University Press, 2012, £24.95 pbk, (9780691154527), 584pp.

Tomas Marttila

The Culture of Enterprise in Neoliberalism: Specters of Entrepreneurship

Abingdon: Routledge, 2013, £80 hbk, (9780415634038), 248pp.

Enterprise and entrepreneurship are frequently constructed within political discourse in terms of economic growth and prosperity. In the UK, for example, the cross-party political consensus on the value of 'the entrepreneur' ensures that this hegemony is rarely questioned. Instead, claims about the creation of economic growth and prosperity through entrepreneurship are repeated to the point that alternative ways of thinking about and doing business start-up and growth fall into disuse, limiting the scope for debate and opportunity. There is a danger that ideologically-driven approaches that draw on the neoliberalism of free markets, deregulation and privatisation but also, in turn, individualism and risk, produce accounts of entrepreneurship that are constrained by being 'caught within a network of social, historical and economic forces' (Ogbor, 2000, p. 624). These accounts create normative understandings that denigrate and exclude alternatives such as non-profit and more collective endeavours. Despite some valuable interventions that seek to question and critique the assumptions of enterprise and small business discourses (for example, Dannreuther and Perren, 2013; Du Gay, 1996; Jones and Spicer, 2005; Keat and Abercrombie, 1991), this review of three recent books on enterprise and entrepreneurship suggests that a need remains for more critical, socially-oriented approaches.

One potentially valuable but under-utilised approach to questioning underlying assumptions in enterprise discourse is to study how enterprise and entrepreneurship have been conducted in different contexts, for example in different geographical and historical contexts. Casson and Casson's The Entrepreneur in History: From Medieval Merchant to Modern Business Leader offers such a standpoint through its historical analysis of 60 entrepreneurship case studies drawn from England since the Medieval period. The authors state that this historical perspective is vital for their audience of students who want to be entrepreneurs but are often taught 'in a superficial way that relies on popular stereotypes rather than rigorous analysis' (p. 2). In seeking to challenge this status quo and to inspire future entrepreneurs, the authors claim that their book will be both authoritative and provocative. 
To achieve this, the book applies Mark Casson's economic theory of entrepreneurship. As utilised here, Casson's theory suggests that entrepreneurship is 'a scarce resource that allows other resources, such as land, labour and capital, to be put to better use', presenting entrepreneurs as those capable of displaying 'good judgement that improves the quality of business decision-making' (Casson and Casson, p. 3). This approach is influential and widely cited. However, as represented in this book, it asserts that, since entrepreneurs necessarily have good judgement, poor judgements are not made by entrepreneurs. This 'success bias' is problematic not least because, contrary to the stated aims of the book, it prevents any critical consideration of enterprise and entrepreneurship. In analysing the historical record from the starting point of Casson's definition and identifying those figures representative of it, the authors are at odds with Schumpeter's call that economic theory should remain the 'servant' and not become the 'master of historical research' (Schumpeter, 1947b, p. 6, cited in Ogbor, 2000, p. 623).

The problem is exacerbated by only attending to those individuals prominent enough in the historical record to provide sufficient material. There is no space for the members of society, such as women or members of minority groups, who might have been engaged in forms of enterprise but remained excluded from the records, or for the small-time, the failed or marginal entrepreneur who is also unlikely to feature. This is important when considering the picture of entrepreneurship and entrepreneurs that is produced from the subsequent analysis. The authors describe the entrepreneur in an impressive variety of roles, acting as coordinator, opportunity-seeker, innovator, pre-emptor, judgemental decision-maker, risk-taker, project manager, team-builder and generalised arbitrageur. They proceed to present a heroic, romanticised image of entrepreneurs as artists, scientists and philosophers, often driven by altruism rather than profit and responsible for the major (beneficial) economic and societal changes in England during the period covered by their study. However, the selection of a small number of case studies that rely on predominance in the historical records and a large degree of success effectively ensures such a romanticised view will emerge from the analysis and escape the sense of authoritative rigor promised in the book's introduction.

Casson and Casson's re-telling of the story of the entrepreneur in history largely becomes one of particular successes. It interprets various aspects of historic commercial and civic activities through a broadly neoliberal lens which foreshortens the historical perspective in terms of context, attitudes and experiences that might otherwise help us understand enterprise and entrepreneurship in more varied ways. Casson and Casson offer an idealised view of enterprise and entrepreneurship that invites neither critical engagement nor consideration of alternative perspectives that may have emerged in different historical contexts but fall outside of Casson's narrow definition of the entrepreneur. The image of the all-conquering, allencompassing entrepreneur at the heart of economic and social change bears little resemblance to the everyday experiences of business start-up and ownership that Casson and Casson's student audience may be anticipated to encounter. Yet it is such idealised views that are eagerly taken up by policy-makers, lobbyists and advisers seeking to promote entrepreneurship and small business.

Landes, Mokyr and Baumol's The Invention of Enterprise: Entrepreneurship from Ancient Mesopotamia to Modern Times similarly seeks to promote understanding of enterprise and entrepreneurship through an historical analysis. This edited collection begins with Mesopotamia and Neo-Babylon and includes analysis of, alongside many detailed chapters on Western economies, the Islamic Middle East, China, Japan and Colonial India. In doing so, it also has the opportunity to discuss different approaches to and interpretations of 
enterprise. However, the book explicitly states its aims as aligned with those of its publishers, The Ewing Marion Kauffman Foundation: 'if the public is to understand the importance of entrepreneurship to economic growth today, people will need to learn more about the role entrepreneurship played in economic growth throughout history' (Foreword, p. vii). The book establishes a particular take on entrepreneurship that is tied to individualism and to economic growth, narrowing the focus of its analysis and adopting a particularly contemporary, neoliberal interpretation of the past that focuses on a specific set of macroeconomic outcomes.

What was partly implicit in Casson and Casson's book is here made very clear: if societies want to overcome problems such as global inequality and poverty then '... part of the answer, if it can be made politically feasible, is the adoption of enhanced incentives for domestic enterprise' (p. 6). In gathering analyses of many historical periods, the editors therefore claim that insights are gained to 'guide those who seek to formulate pertinent policy - policy to encourage economic growth via the use and dissemination of innovation and policy for the containment and even the elimination of poverty' (Implications, p. 527). It is in adopting this focus on economic growth and in seeking to address contemporary policy-makers that the historical analysis of societies and particular social actors risks distortion.

It is a detailed book, presenting richer and more nuanced case studies than Casson and Casson. There are interesting observations such as situating the emergence of enterprise in Neo-Babylonian temples and palaces rather than with lone traders, an important context for understanding the social, processual nature of entrepreneurship. Importantly, a chapter on 'Entrepreneurs and Entrepreneurship in Medieval Europe' adds some weight to this when it notes that 'the relative absence or unimportance of the standalone entrepreneur did not preclude economic growth' (p. 105). Taken as a whole, the book also highlights the role of government, for example in supporting relevant institutions and discouraging rent-seeking behaviours, a role which can be overlooked among some of the accompanying hyperbole around individual heroism.

Mark Casson co-authors two chapters and his general arguments are in tune with the majority of the book. His definition of entrepreneurship, as outlined above, can be contrasted clearly with the everyday practice of small business start-up and ownership: '... many small firms that are "entrepreneurial" in the sense of being run by self-employed owner-managers may not be entrepreneurial in the sense described here, because their owner-managers lack ability; they have poor judgement that leads to a below-average rate of profit' (Britain 1830-1900, p. 225). This again suggests that we can only judge whether someone is really an entrepreneur after the fact, when their profit margins reveal the extent of their supposed good judgement.

As in Casson and Casson's book, many of the authors in this collection assess different cultures through an apparently neoliberal lens, with a free market, individualistic culture taken as a benchmark and other cultures presented as 'barred from the new ways [of enterprise] by political misfortune and cultural impediments' (Introduction, p. 2). Such cultural impediments include, for example, the egalitarian 'Islamic inheritance system [which] made it difficult to preserve a successful enterprise' (Entrepreneurship in Middle Eastern History, p. 69). Further, observations are offered such as: 'France is the European country where creation of companies is seen as most difficult [hence] why so many French are now living and working abroad' (Entrepreneurship in France, p. 322). This triumphalist view of history, reading the past through our own, taken-for-granted and unquestioned neoliberal present generates only limited insight or new understanding. 
The Culture of Enterprise in Neoliberalism: Specters of Entrepreneurship by Tomas Marttila is more focused in its analysis and targeted more specifically at an academic audience, detailing the changes in Swedish political discourse that created a dominant role for entrepreneurship after the 1980s. While acknowledging that Casson's original work has 'elaborated one of the few cohesive economic theories of entrepreneurship' (p. 8), Marttila adopts a post-structural discourse approach to analyse Swedish government texts, such as policy papers, to provide a detailed overview of political change and debate around work and entrepreneurship between 1991 and 2004. This analysis details how neoliberal ideas of enterprise and growth were appropriated by different governments and for supposedly different political agendas. In the process, the entrepreneur was promoted as a neoliberal role model by governments seeking to 'actively support the replacement of social relations and interchanges of solidarity, trust, and empathy with the logics of economic contract, competition and investment' (p.18).

What Marttila's analysis uncovers is the enterprise culture as it has been critiqued by theorists such as Paul Du Gay, perpetuating an ideology of individualism with entrepreneurship as its ideal. Not only has this enterprise discourse colonised different areas of government policy and forms of work, it also has important influences on the construction of individual subjects (Du Gay, 1996). The political changes and adoption of enterprise discourse that Marttila records in detail are familiar from studies of those in the UK and other western contexts (for example, Dannreuther and Perren 2013; Keat and Abercrombie, 1991). However, Marttila's exclusive focus on documents precludes any significant engagement with their wider significance such as broader policy implications or how their construction of entrepreneurship has impacted on individual business owners. Perhaps as a result, the book does not offer much that is new beyond its specific empirical focus.

What Marttila does demonstrate is how Swedish political discourse has experienced a 'remarkable dissemination of the culture of enterprise into unforeseen social practices and situations' (p. 26), that is, into universities, large organisations and other new territories (see also, Du Gay, 1996). This multitude of meanings is set against the claims of others such as Jones and Spicer (2005) that 'entrepreneur' is an empty signifier, that it has an 'essential and inescapable ambiguity' (p. 16). For Marttila it is, instead, interpreted as a floating signifier. Instead of 'entrepreneur' lacking a distinctive meaning, the meaning has moved elsewhere, transposed into new practices and situations and with alternative uses in different contexts. Importantly, Marttila suggests that this is an 'enrichment' of the term rather than it losing any determinate meaning. He argues for this enrichment by drawing on the Lacanian concept of a nodal point to describe how enterprise, as a signifier, productively associates different discourses to construct 'cultural hybrids'. This process of association allows a greater number of people (pupils, employees, social activists) to become entrepreneurs within their specific contexts and, in turn, to be associated with those 'entrepreneurial characteristics' (p.202) lauded by, for example, the other books under review.

However, it is not entirely clear why the opportunity to become an entrepreneur in these different contexts is necessarily valuable, especially when considering the restrictive understandings of entrepreneurship that exclude a great deal of everyday practice. Marttila is less interested in the relation of these discourses to power and domination, contrasting his work with that of Jones and Spicer in terms of his claims for a systematic analysis that avoids any urge to critique contemporary portrayals or experiences of entrepreneurship or to 'question the regimes of domination that are constructed and perpetuated in the name of the entrepreneur' (Jones and Spicer, cited in Marttila, p. 204). Marttila suggests that his work 
escapes the dangers of adopting an alternative, equally value-laden discursive position and is, instead, aligned with the deconstructive work of Ogbor (2000), focused on questions of how and why. However, where Ogbor (2000, p. 627) argued for analysis of the ideology of entrepreneurship as 'one possible way of breaking out of the problems involved in the premature closure of new and unconventional ideas', Marttila's book goes little beyond describing the status quo.

Marttila recognises that definitions of 'entrepreneur' and the discourses surrounding them are socially and historically bounded, that we cannot assume the definition we use today can be forced into different contexts without any adaptation or adjustment. In contrast, the other books under review (re)shape their interpretations of history around relatively fixed conceptions of enterprise and entrepreneurship, seeking to demonstrate their value and importance. This reinforces an understanding of entrepreneurship that, in its romanticism, excludes much of what is involved in the relatively banal, everyday practice of those who set up and run businesses. Further, such a normative approach ignores or misrepresents sections of society such as women and ethnic minority entrepreneurs (Hamilton, 2013; Ogbor, 2000) as well as less individualistic or non-profit endeavours. These discursive silences and processes of exclusion from established normative understandings of entrepreneurship perpetuate a hegemonic and narrow view focused on promoting a neoliberal role for selfemployment and individualism while squeezing out alternative ways of thinking about and doing business and organising society.

Where the first two books aim to inform students, potential entrepreneurs and policy makers, this narrow view is worrying and worthy of challenge, not only description. There is a danger for academics since, by relating their research to this ideologically-motivated enterprise discourse, they are able to link their work to institutionalised power, to gain legitimacy in terms of increasing calls for relevance and impact (Dannreuther and Perren, 2013). Interpreting social phenomena around business start up and ownership in terms of this discourse creates a marginalised, silenced majority of those outside the prescribed norm. It is important to study those who adopt different models, for example through communityfocused enterprises or lifestyle businesses, and those who are not readily captured by a discourse that is 'discriminatory, gender-biased [and] ethnocentrically determined' Ogbor (2000, p.629) and are therefore ignored by surveys or other measures of entrepreneurial activity (Hamilton, 2013). What is also lacking in the resultant research agenda, as well as from the broader policy debates and from the resources provided to practitioners, is an understanding of how entrepreneurs take-up, use, ignore or are excluded from this dominating form of societal discourse. The academic community needs to provide new ways of looking at entrepreneurship and to talk to different types of entrepreneur, such as those who are excluded from the dominant, ideological conceptions of entrepreneurship.

Incorporating into mainstream debate different ways of conceiving of, discussing and enacting enterprise and entrepreneurship can open up further possibilities for how these aspects of work and society are organised. To uncover and understand these alternatives, there is an urgent need to challenge the underlying neoliberal assumptions that pervade or are merely described uncritically by the books under review. The current hegemony of neoliberalism surrounding enterprise and entrepreneurship is, after all, just one possible perspective. Sites of study may need to change, for example to focus on a greater role for the socially-embedded nature of entrepreneurship or to embrace possibilities of difference in historical or geographical contexts that escape easily-accessed records or popular folklore. Further, contrary to Marttila, it is insufficient to see existing entrepreneurial characteristics 
[Type here]

made accessible to new groups and, instead, as researchers we should seek to revise our understanding of what enterprise and entrepreneurship can be. Paying greater attention to the silenced majority can make more meaningful contributions to policy and research by focusing on 'what is' or what 'could be' rather than ideological prescriptions of what 'should be'.

\section{References:}

Dannreuther C and Perren L (2013) The political economy of the small firm. Abington: Routledge.

Du Gay P (1996) Consumption and identity at work. London: Sage Publications Ltd.

Hamilton E (2013) The discourse of entrepreneurial masculinities (and femininities). Entrepreneurship \& Regional Development 25(1-2): 90-99.

Jones C and Spicer A (2009) Unmasking the entrepreneur. Cheltenham: Edward Elgar Publishing Ltd.

Keat R and Abercrombie N (1991) Enterprise culture. London: Routledge.

Ogbor JO (2000) Mythicizing and reification in entrepreneurial discourse: Ideology-critique of entrepreneurial studies. Journal of Management Studies 37(5) 605-635. 